\title{
Spontaneous esophageal perforation in eosinophilic esophagitis in children
}
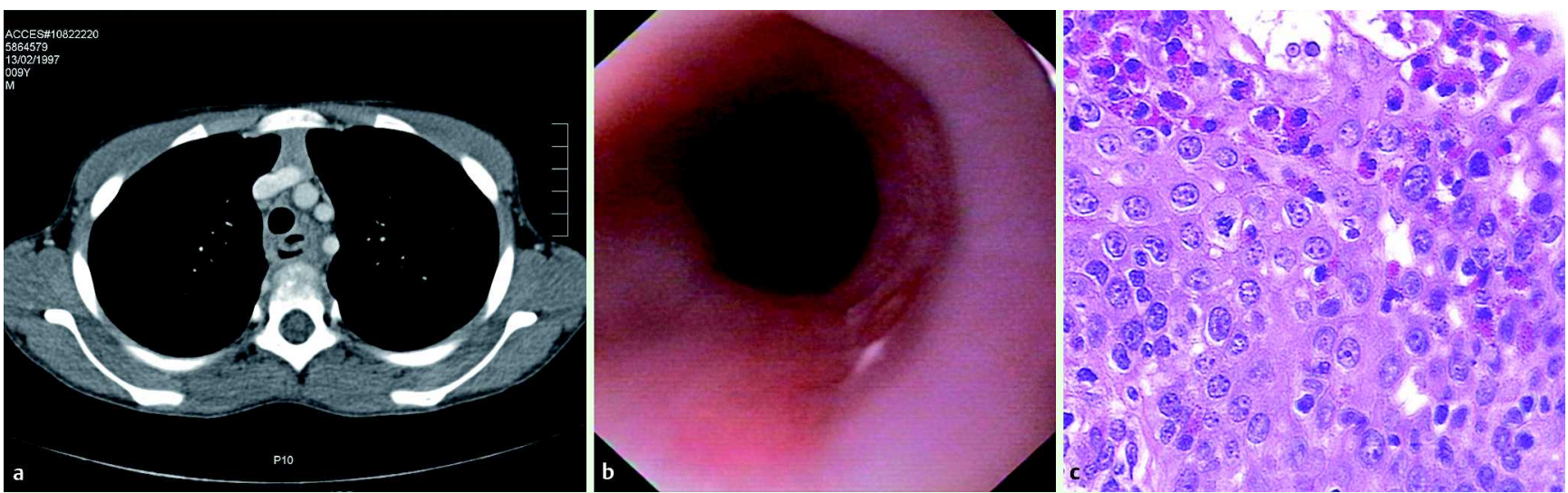

Fig. 1 a Chest computed tomography scan showing an upper third retroesophageal perforation, with a periesophageal fluid collection ( $20 \times 10 \mathrm{~mm})$. b Esophageal endoscopy. c Biopsy showing intraepithelial eosinophil aggregates.

A 9-year-old girl with a history of asthma, intermittent solid food dysphagia and blockage was admitted because of chest pain, pyrosis, and fever $\left(38.3^{\circ} \mathrm{C}\right)$. The only medication she was on at the time of our evaluation was the inhaler Salbutamol-sulfate, which she used as needed. Symptoms started a few hours after a food blockage episode. Physical examination was normal, except for tachycardia (135 bpm). Laboratory results showed: leukocytosis $\left(17300 / \mathrm{mm}^{3}\right), 11.59 \times 10^{9}$ neutrophils, a high C-reactive protein $(180 \mathrm{mg} / \mathrm{l})$, and erythrocyte sedimentation rate of $74 \mathrm{~mm} / \mathrm{h}$.

Chest radiograph was normal. Chest computed tomography scan ( $\mathbf{F i g . 1 \mathbf { a } )}$ showed a retroesophageal perforation, with periesophageal fluid collection. Initial treatment consisted of fasting, intravenous antibiotics (ceftriaxone $1.5 \mathrm{~g} / \mathrm{d}$, metronidazole $300 \mathrm{mg}$ t.i.d, gentamicin $90 \mathrm{mg} / \mathrm{d}$ ), and proton pump inhibitor $(30 \mathrm{mg} / \mathrm{d})$, with good evolution. Upper endoscopy ( $\bullet$ Fig. 1b) 2 months later showed an upper esophageal resistance to the tube passage without stenosis, and normal mucosa. Biopsies demonstrated very many intraepithelial eosinophil aggregates $>20$ eos/HPF ( $\bullet$ Fig. 1 c).

Eosinophilic esophagitis is characterized by esophageal and/or upper gastrointestinal tract symptoms in association with an esophageal mucosal biopsy containing $\geq 15$ intraepithelial eos/HPF in one or more biopsy specimen, without pathologic gastroesophageal reflux disease (GERD) [1]. Eosinophilic esophagitis is a rare chronic inflammatory disease, with a varied clinical and endoscopic spectrum. Some age-related differences were noted between symptoms in children and adults. In children, feeding refusal or intolerance, GERD-like symptoms, emesis, abdominal pain, dysphagia, food impaction, chest pain, and diarrhea have been described [1]. In adults, intermittent dysphagia and food impaction are more common [1]. Transmural inflammation has been reported in eosinophilic esophagitis. It significantly increases the risk of perforation. Mucosal laceration and transmural perforation have been reported after endoscopy or dilation in eosinophilic esophagitis $[2,3]$.

Spontaneous esophageal perforation was recently reported in three adults, associated with eosinophilic esophagitis [24]. Until now, no reports of this unusual association and presentation have been reported in children, extending the clinical spectrum of eosinophilic esophagitis in this population.

Endoscopy_UCTN_Code_CCL_1AB_2AC_3AD

\section{Robles-Medranda ${ }^{1,2}$, F. Villard ${ }^{3}$,}

R. Bouvier ${ }^{4}$, J. Dumortier ${ }^{1}$, A. Lachaux ${ }^{2,3}$ Department of Hepatogastroenterolo-

gy, Hôpital Edouard Herriot, Lyon,

France

CMR-Wilson, Edouard Herriot Hospital, Lyon, France

Pediatrics Department, Hôpital Edouard Herriot, Lyon, France

Pathology Department, Hôpital Edouard Herriot, Lyon, France

\section{References}

1 Furuta GT, Liacouras CA, Collins $M H$ et al. Eosinophilic esophagitis in children and adults: a systematic review and consensus recommendations for diagnosis and treatment. Gastroenterology 2007; 133: $1342-$ 1363

2 Ligouri G, Cortale M, Cimino F et al. Circumferential mucosal dissection and esophageal perforation in a patient with eosinophilic esophagitis. World J Gastroenterol 2008; 14: 803-804

3 Cohen MS, Kaufman AB, Palazzo JP et al. An audit of endoscopic complications in adult eosinophilic esophagitis. Clin Gastroenterol Hepatol 2007; 5: 1149-1153

4 Gomez Senent S, Adan Merino L, Froilan Torres $C$ et al. Spontaneous esophageal rupture as onset of eosinophilic esophagitis. Gastroenterol Hepatol 2008; 31: 50-51

5 Cohen MS, Kaufman A, Dimarino A et al. Eosinophilic esophagitis presenting as spontaneous esophageal rupture (Boerhaave's syndrome). Clin Gastroenterol Hepatol 2007; 5: A24

Bibliography

DOI $10.1055 / \mathrm{s}-2007-995801$

Endoscopy 2008; 40: E171

(c) Georg Thieme Verlag KG Stuttgart · New York ISSN 0013-726X

\section{Corresponding author}

\section{Robles-Medranda, MD}

Hôpital Edouard Herriot

Department of Hepatogastroenterology

Place d'Arsonval

69437, Lyon

Cedex 03

France

Fax: +33-472-110147

carlosoakm@yahoo.es 